\title{
Protez sisteminde yenilik: PENTA modüler uzuv tamir sistemi
}

\section{Innovation in prosthetic system: PENTA modular extremity reconstruction system}

\author{
Harzem Özger ${ }^{1}$, Buğra Alpan² \\ 1 İstanbul Ortopedik Onkoloji Grubu, İstanbul \\ ${ }^{2}$ Acıbadem Mehmet Ali Aydınlar Üniversitesi, Tıp Fakültesi, Ortopedi ve Travmatoloji Ana Bilim Dalı, İstanbul
}

PENTA-MUTS (PENTA - Modüler Uzuv Tamir Sistemi); kalça, diz, omuz ve dirsek eklemlerinde tümör rezeksiyonu, revizyon artroplastisi ve travma sonucu ortaya çıkan ve tamir edilemeyen defektlerin rekonstrükte edilmesi için tasarlanmış bir implant sistemidir. Sistemin farklı parçaları, Ti6Al4V, CoCrMo ve ultra yüksek molekül ağırlıklı polietilen (UHMWPE) kullanılarak üretilmiştir. Sistemin tasarımının arkasındaki felsefe ve başlıca faydaları, ankoraj (tutunma), modülerlik ve eklemleşme özellikleri ile açıklanabilir. İmplant sisteminin ismi olan "PENTA", özellikle çimentosuz yerleştirmeye yönelik geliş̧irilmiş olan protez sapının "beşgen/pentagonal” kesitinden gelmektedir. Modüler parçalar, üç farklı özelliğin kombine edildiği bir mekanizmayla birleştirilir: rotasyonel ayarlamayı sağlayan dişli bağlantı, press-fit sıkışan konik bağlantı, aksiyel transfiksasyon civatası. PENTA diz megaprotezi, rotasyonel bir menteşe eklem sistemine sahiptir. Femoral ve tibial komponentler fleksiyon-ekstansiyon hareketine ve serbest rotasyona izin veren bir "boyunduruk mekanizması" (tibial rotasyon parçası) ile birbirine bağlanır. Hiperekstansiyon, "bumper insert" adı verilen polietilen pir parça ile kısıtlanır. Rotasyon mekanizması, rotasyonun uç noktalarında hareket yumuşak şekilde sonlandırılacak şekilde tasarlanmıştır.

Anahtar sözcükler: uzuv kurtarııı cerrahi; tümör protezi; megaprotez; modüler implant; tümör rezeksiyonu; kemik tümörü; masif kemik defekti; diz instabilitesi; travmatik kemik defekti; revizyon artroplastisi
PENTA-MERS (PENTA - Modular Extremity Reconstruction System) is a set of implants designed to reconstruct irreparable defects involving the hip, knee, shoulder and elbow joints caused by tumor resection, revision arthroplasty or trauma. Different parts of the implant system are made of A Ti6Al4V, CoCrMo. and ultra high molecular weight polyethylene (UHMW-PE). The design rationale and main advantages of the implant system can be described in relation to its anchorage, modularity and articulation characteristics. The name of the implant "PENTA" is derived from the pentagonal cross-section of its stem, which particularly favors cementless implantation. Modular parts are secured with 3 different features combined: a toothed-connection which allows rotational adjustment, a conical press-fit connection and an axial transfixation bolt. PENTA knee megaprosthesis has a rotational hinge mechanism, which connects the femoral and tibial components through a yoke assembly (tibial rotation piece). Hyperextension is curbed by a bumper insert on the yoke while the rotational parts are designed to provide a smooth stop at the endpoints of rotation.

Key words: limb salvage surgery; tumor prosthesis; megaprosthesis; modular implant; tumor resection; bone tumor; massive bone defect; knee instability; traumatic bone defect; revision arthroplasty

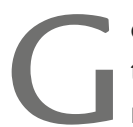

örüntüleme yöntemleri, kemoterapi ve radyoterapi gibi adjuvan tedavi modaliteleri ve cerrahi tekniklerdeki gelişmeler ile ve ortopedik onkoloji alanında artan bilgi ve tecrübe sonucunda kas-iskelet sistemi tümörlerinde uzuv kurtarıcı cerrahi günümüzde ana tedavi yöntemi haline gelmiştir. ${ }^{[1-6]}$ Cerrahi cihaz ve implantların tasarım, üretim ve uygulamasındaki ilerlemeler de amputasyon yerine uzuv kurtarıcı cerrahinin tercih edilmesinde büyük rol oynamaktadır. Uzuv kurtarıcı cerrahide en sık kullanılan yöntem ise rezeksiyon sonrası oluşan defektin bir tümör protezi (megaprotez) ile rekonstrükte edilmesidir. ${ }^{[2-6]}$ Diz çevresi (distal femur ve proksimal tibia), omuz (proksimal humerus), kalça (proksimal femur) ve dirsek çevresi (distal humerus), primer kas-iskelet sistemi tümörlerinin sıklıkla tuttuğu anatomik bölgelerdir. Bunların arasında diz eklemi rekonstrüksiyonu, uzuv kurtarıcı cerrahinin özellikle genç yaş grubunda en sık uygulandığı bölge olması ve yük altında yüksek fonksiyon beklenmesi nedeniyle özellik taşır. ${ }^{[1,3-6]}$ Genç hastaların aktivite düzeyinin yüksek olması ve tümör rezeksiyonu nedeniyle diz çevresi statik ve dinamik stabilizatörlerin kaybı, diz megaprotezlerinin yüksek makaslama, burulma ve eğilme kurvetlerine maruz kalmasına ve yetmezlik gelişmesine yol açmaktadır. Megaprotezlerin tasarımı, rekonstrüksiyonun sağkalımında büyük önem taşır.

- Illetişim adresi: Prof. Dr. Harzem Özger, Terrace Fulya Center 1 Kat:10, D:51 Hakkı Yeten Cad. No. 11, 34394 Şişli, İstanbul Tel: 0532 - 6106302 e-posta: harzemo@yahoo.com ORCID ID: 0000-0001-5033-7531

- Geliş tarihi: 28 Kasım $2020 \quad$ Kabul tarihi: 8 Aralık 2020

Buğra Alpan, ORCID ID: 0000-0002-2573-8605 
Tümör protezleri, ancak 1990'ların başından itibaren ülkemizde kullanılabilir hale gelmiştir. Daha önceki dönemlerde, o zaman için yalnızca ithal olarak temin edilebilen bu megaprotezler, ekonomik, lojistik ve bürokratik sorunlar ve ülkemizde uzuv kurtarıcı cerrahi alanında özelleşmiş merkezlerin olmayışı nedeniyle kullanılamamıştır. "Ortopedik onkoloji” alanının bilinirliği ve uygulamalarının artmasıyla birlikte önce yerli ve son derece basit tasarıma sahip bir tümör protezi ile bu sorun aşılmaya çalışıımıştır. 1993-2008 yılları arasında ülkemizde, ilk yerli protez tasarımının revize edilmiş yeni versiyonları ve uluslararası başlıca protez firmalarının implantları dahil pek çok proteze erişim imkanı elde edilmiş fakat sosyal güvenlik politikalarındaki ve ithalatçı firmaların tutumlarındaki değişiklikler nedeniyle bu implantlara erişimde süreklilik sağlanamamıştır. ${ }^{[7]}$ Yine aynı dönemde, başlıca ithal tümör protezlerindeki bazı tasarım hatalarının spesifik komplikasyonlara yol açtığı klinik olarak tecrübe edilmesine rağmen yerli tümör protezlerinin tasarım ve üretim kalitesinin ithal implantların gerisinde kaldığı görülmüştür ${ }^{[7]}$. Hem uzuv kurtarıcı cerrahide non-biyolojik rekonstrüksiyonun ana unsuru olan tümör protezlerine erişimin sürekli kılınması hem de en üst düzey protez sağkalımı ve uzuv fonksiyonu elde edilebilmesi amacıyla yeni bir yerli implant sistemi geliştirilmesi ihtiyacı doğmuştur. İmplant sistemi tasarlanırken önceki farklı implant sistemlerinin kuvvetli yönleri göz önünde tutulmuştur.

Tasarlanan implant sistemi[ ${ }^{[8]}, 2009$ yılından itibaren TIPSAN (İzmir, Türkiye) firması tarafından üretilmeye başlanmış, Sağlık Bakanlığı ve Sosyal Güvenlik Kurumu'ndan gerekli izinlerin ve ruhsatlandırma işlemlerinin tamamlanmasının ardından da klinik kullanıma girmiştir. İmplant sisteminin tasarımı ile ilgili 2010 yılında T.C. Türk Patent Enstitüsüne patent başvurusu yapılmış ve 2013'te patent tescillenmiştir (Tablo 1). ${ }^{[8]}$

\section{T. C. Türk Patent Enstitüsü'ne Faydalı Model Belgesi için Başvuru Bilgileri[ ${ }^{[8]}$}

Başvuru bilgileri Tablo 1'de gösterilmiştir. ${ }^{[8]}$

Tablo 1. Başvuru bilgileri ${ }^{[8]}$

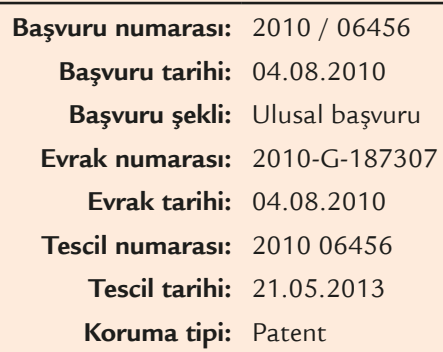

\section{FAYDALI MODEL BELGESI - No: TR $201006456^{[8]}$}

\section{Teknik Alan ${ }^{[8]}$}

"Mevcut buluş, ortopedik onkolojik cerrahide kullanılmak üzere tasarlanmış modüler bir megaprotez implant sistemi ile ilgilidir. Bu megaprotez sistemi, öncelikle ve özellikle kas-iskelet sistemi tümörlerinin rezeksiyonu sonrasında omuz, dirsek, kalça, diz eklemleri ve humerus, femur ve tibia kemiklerinde ortaya çıkan defektlerin rekonstrüksiyonu için tasarlanmıştır. Bununla beraber mevcut buluş, revizyon artroplastisi veya travma ile ilişkili tamir edilemeyecek kemik kayıpları ve kronik çoklu bağ yaralanmaları ile kemik deformitelerine bağlı ağır eklem instabilitelerinin tedavisinde de kullanılabilecektir (Şekil 1). [8]"

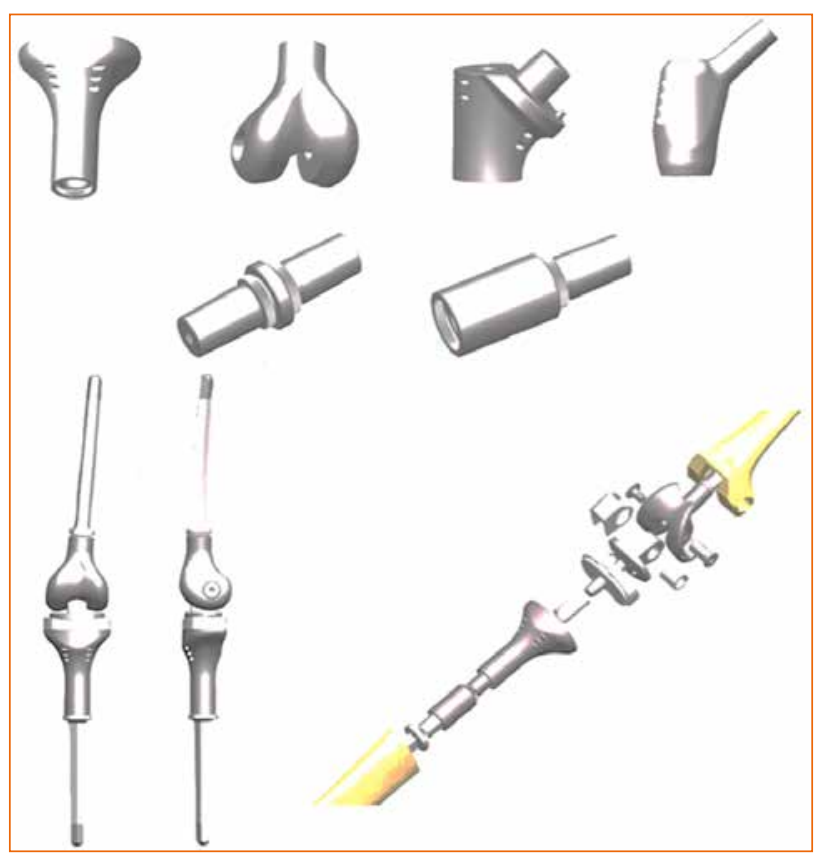

Şekil 1. Üstte PENTA-MUTS megaprotez sisteminin bazı gövde, uzatma ve bağlantı parçaları, altta ise diz megaprotezinin monte ve demonte halini gösteren çizimler görülmekte.

\section{Önceki Teknik/Teknikler ${ }^{[8]}$}

"Modern anlamda özellikle son dört dekaddır yukarıda belirtilen türdeki kemik ve eklem kayıplarının rekonstrüksiyonu amacıyla özel yapım (hastadaki defekte özel olarak preoperatif imal edilen) veya modüler (intraoperatif ayarlamalara izin veren kapsamlı implant sistemi) özellikte pek çok megaprotez tasarlanmış, üretilmiş ve klinik uygulamaya sokulmuştur. ${ }^{[2-7]}$ Daha yaygın olarak kullanılan modüler megaprotez sistemleri arasındaki temel farklılıklar, üç ana özellik etrafinda şekillenmektedir. Bunlar ankoraj (tutunma), modülerlik ve eklemleşme özellikleridir. Bununla birlikte implantların imal edildiği alaşım ve diğer non-metalik 
materyaller ile protez uygulamasının neden olduğu kemik stoğu kayıpları gibi faktörler de megaprotez sistemleri arasında fark yaratır. Megaprotez sistemleri genellikle çoklu anatomik bölgenin (diz, kalça, omuz, dirsek) rekonstrükte edilebileceği kapsamlı implant setleri şeklinde tasarlansa da sistemler arasındaki farklar özellikle diz çevresi rekonstrüksiyonlarda belirgin şekilde ortaya çıkar. ${ }^{[7]}$ Mevcut buluşun tasarım ve üretimi öncesinde ülkemizde ağırlıklı olarak kullanılan bazı megaprotez sistemleri Tablo 2'de listelenmiştir. Bu listedeki ithal megaprotez sistemleri aynı zamanda uluslararası ortopedik onkoloji camiasında da yaygın kabul gören ve dünyanın önde gelen ortopedik onkoloji merkezlerinde değişik versiyonlarıyla uzun yıllar kullanılmış sistemlerdir.

Özel yapım protezlerin dezavantajları, yüksek maliyet, üretim için ameliyat öncesi belli bir süreye ihtiyaç duyulması ve ameliyat öncesi planlamada hata yapıldıysa ameliyat sırasında uygulama güçlügü ve hatayı telafi edebilecek alternatif bulunmaması olarak sayılabilir. Modüler protezlerin dezavantajları ise parçalar arasındaki bağlantı noktalarının sistemin zayı noktalarını oluşturarak kırılma ve ayrılma gibi komplikasyonlara yol açması ve genellikle setteki protez komponentlerinin her türlü yapısal veya patolojik anatomik varyasyonu kapsayacak şekilde geniş bir yelpazede üretilmemiş olmasıdır.

Uzuv kurtarıcı cerrahi uygulanan hastaların sağkalım sürelerinin artmasıly birlikte megaprotezlerin uzun dönem komplikasyonları görülmeye başlanmıştır. Başlıca komplikasyonlar protezde gevşeme, enfeksiyon, kırılma ve çıkıktır. ${ }^{[2-7]} \mathrm{Bu}$ komplikasyonlar protezin tamamen veya kısmen revize edilmesini gerektirmektedir. Özellikle çimentolu protez uygulamaları, revizyon açısından büyük sorun yaratmaktadır çünkü gevşeme genellikle protez-çimento ara yüzünden kaynaklanmakta oysa çimento-kemik ara yüzünde tutunma sağlam kalmaktadır. Kemiğin içinde kalan çimento parçalarının temizlenmesi önemli miktarda kemik kaybına ve kırıklara yol açmakta ve revizyon protezinin yerleştirilmesini güçleştirmektedir. Ithal edilen protezlerin bir kısmı çimentolu bir kısmı çimentosuz uygulanırken, mevcut buluş öncesinde kullanılan tek yerli protez çimentolu uygulamaya yönelik tasarlanmıştır. ${ }^{[7]}$
Hem çimentolu hem de çimentosuz uygulanan protezlerde önemli bir gevşeme nedeni, hareketli yüzeylerde kullanılan insert adı verilen polietilenden üretilmiş parçalardan aşınma sonucu partikül dökülmesidir. Vücudun savunma mekanizması nedeniyle kemik hücrelerinin dökülen partikülleri yakalayarak hücre içine alması, kemikte lizis olmasına, hem çimento-kemik hem de protez-kemik ara yüzünde zayıflama olmasına yol açmaktadır. Sonuç gevşeme ve lizise bağlı kemik kaybıdır. Polietilenin aşınma direncinin düşük olması daha fazla partikül dökülmesine ve gevşemeye neden olmaktadir.

Çimentosuz protezlerin kemik içinde tutunmasını arttırmak için protez stemlerinde pek çok geometrik tasarım uygulanmıştır. Silindirik ve altıgen kesitli stemlerin primer rotasyonel stabilitesi her zaman istenilen ölçüde olmamaktadir.

Paslanmaz çelikten üretilen protezler ağır olmakta ve hareketi güçleştirmektedir. Protezin sabit kısımlarından elektroliz nedeniyle ya da hareketli kısımlarından sürtünme ile dökülen metal partikülleri de ayrı bir problem yaratmaktadır. Bu partiküller metallozis adı verilen doku yanıtına ve nadiren de olsa metal alerjisine yol açabilmektedir.

Megaprotezlerde diz eklemi sabit menteşeli, kontrollü rotasyonel ve kontrolsüz rotasyonel menteşeli olarak üç ana grupta tasarlanmıştır. ${ }^{[7]}$ Bunlardan sabit menteşeli protezler fizyolojik diz eklem hareketine uyum göstermemektedir. Kontrollü rotasyon sistemlerinde rotasyonun uç noktalarında ortaya çıkan ani durma hareketi protez sapına yüksek rotasyonel yükler binmesine ve dolayısıyla gevşemeye yol açmaktadır. Ayrıca ani durma sırasında komponentlerin birbirine vurma sesi hastaya rahatsızlık verebilmektedir. Kontrolsüz rotasyon sistemlerinde ise protezde çıkma sorunu görülmektedir.

Mevcut megaendoprotezlerde, proksimal tibia rezeksiyon protezinin femoral komponenti yerleştirilirken önemli miktarda sağlam kemik kaybı oluşmaktadır. Bu kemik kaybı, ileride gerekebilecek revizyon ve kurtarma girişimlerinde önemli bir sorun teşkil etmektedir.

ithal protez sistemlerinin maliyetleri yüksektir ve kısmi revizyonlar açısından parça devamlıı̆̆ı să̆lanamamaktadır."

Tablo 2. 1993-2008 yılları arasında ülkemizde kullanılan başlıca modüler megaprotez sistemleri

\begin{tabular}{lll}
\hline Megaprotez sistemi & Ankoraj & Eklem menteşesi \\
\hline TMTS (Hipokrat, İzmir, Türkiye) & Çimentolu & Fikse \\
FINN (Biomet, Warsaw, IN, USA) & Çimentolu/çimentosuz & Rotasyonlu \\
HMRS KOTZ (Stryker Corp., Mahwah, NJ, USA) & Çimentosuz, ekstrakortikal flanş & Fikse/rotasyonlu \\
MUTARS (Implantcast GmbH, Buxtehude, Germany) & Çimentolu/çimentosuz, altıgen kesitli & Rotasyonlu \\
\hline
\end{tabular}

TMTS, Turkish Musculoskeletal Tumor Society. 


\section{Buluşun Kısa Tarifi[ ${ }^{[8]}$}

"Buluş, omuz, kalça, diz ve dirsek eklemleri ile bu eklemlere komşu humerus, femur ve tibia kemiklerinde başta tümör rezeksiyonu olmak üzere, revizyon artroplastisi, çok parçalı kırıklar, çoklu bağ yaralanması ve deformite gibi nedenlere bağlı olarak ortaya çıkan tamir edilemeyecek kemik ve eklem kayıpları ile kronik eklem instabilitelerinin tamamını rekonstrükte edebilecek bir modüler megaprotez sistemi ile, bu sistemin içinde yer alan, protez-kemik arayüzünde stabiliteyi arttıran beşgen kesit yapısına ve uç kısmına doğru daralan konik yapıya haiz stemler, bu stemlerin kemiğe gömülmesini önleyen yakalık ve sapla yakalık arasındaki oval eğimli yüzeyler ile ilgilidir (Şekil 2). ${ }^{[8] "}$

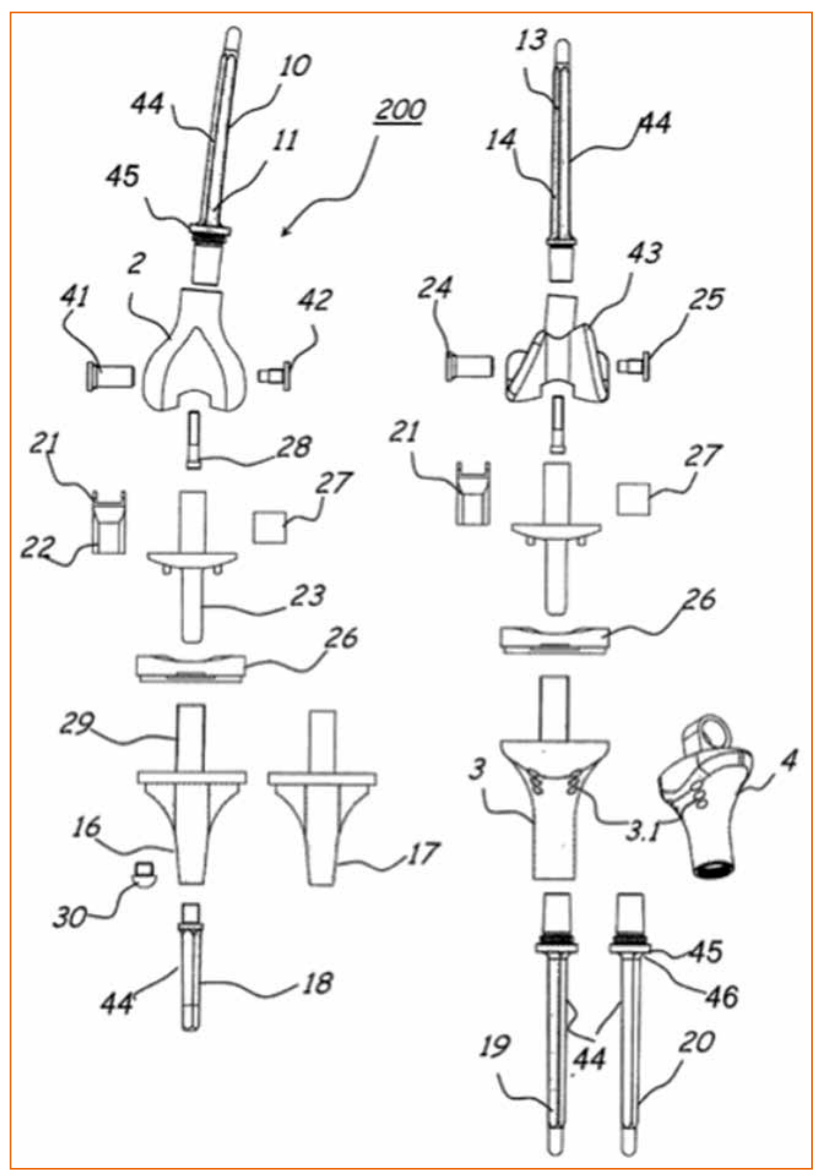

Şekil 2. Solda distal femur, sağda ise proksimal tibia rezeksiyon protezlerinin demonte çizimlerinde patent istemine tabi komponentler ve komponent kısımları $(11,12,13,14,15,18$, 19, 20, 32, 33, 44, 45, 46) görülmekte.

\section{Buluşun Detaylı Açıklanması ${ }^{[8]}$}

"PentaMUTS, yüksek modüler özelliğe sahiptir. Yüzey ve komponent çeşitliliği sayesinde değişik klinik koşullarda intraoperatif çözüm sağlamaktadır. Kalça ve diz eklemlerini rekonstrükte eden tüm femur ve tibia gövde, bağlantı ve uzatma parçaları birbiri ile uyumludur ve modülerdir. Aynı şekilde omuz ve dirsek eklemlerini rekonstrükte eden tüm humerus gövde, uzatma ve bağlantı parçaları da birbiri ile uyumludur ve modülerdir.

PentaMUTS tüm gövde, bağlantı ve uzatma parçaları Ti6Al-4V malzemeden üretilmiştir ve böylece hem hafif hem dayanıkı olması sağlanmıştır. Proksimal tibia rezeksiyon protezinin femoral komponenti, standart olarak CoCrMo malzemeden üretilmiş olup proksimal tibia ve distal femur gövdeleri ve tibial baseplate için de CoCrMo seçeneği mevcuttur.

Ti-6Al-4V malzemeden üretilmiş parçalara, AMS 2488 $D$ şartnamesine uygun olarak anodizasyon uygulanmıştır. $B u$ işlem, enfeksiyon, çizilme ve aşınma direncini arttırmaktadır.

Sistemin diz eklemi fizyolojik diz hareketini taklit edecek şekilde $16^{\circ}$ iç ve dış rotasyona izin veren kontrollü rotasyonel menteşe yapısındadır. Tibial rotasyon parçasının alt yüzeyindeki iki adet rotasyon sınırlayıcı çıkıntı, tibial insert üzerindeki kanallar içerisinde hareket etmektedir. Mevcut diğer sistemlerde kullanılan benzer rotasyon sınırlayıcı çıkıntılar, içinde hareket ettikleri yarığın uç noktalarına sert şekilde çarpmakta iken PentaMUTS'ta konkav yapıdaki tibial insert üst yüzeyi, uç noktalarda rotasyon hareketini yavaşlatarak durduracak şekilde tibial rotasyon parçasının konveks alt yüzeyi ile eşleşmektedir. Ancak, ileri dereceli adale rezeksiyonu gerektiren ve rotasyonun kontrol edilemeyeceği durumlarda rotasyonsuz sabit menteşeli eklem seçeneği mevcuttur.

Sistemde intramedüller fiksasyon öncelikle sementsiz, hidroksiapatit (HA) kaplı titanyum stemlerle sağlanmaktadır. Hidroksiapatit kaplamaları, ASTM F 1185 ve ISO 137791 standartlarına uygun olarak yapılmıştır. Bu stemler, PentaMUTS sistemine özgü antirotasyonel beşgen (pentagonal) yapıdadır. Beşgen kesit, silindirik ve altıgen kesitli stemlere göre daha yüksek rotasyonel stabilite sağlamaktadır.

PentaMUTS sisteminde, medüller kanalın aşırı geniş ya da kemik kalitesinin yetersiz olduğu durumlarda güvenilir fiksasyon için sementli stem seçenekleri de mevcuttur. Sementli stemler kaba kumlamalıdır.

Stemlerin zamanla diafizer kemiğin içine gömülmesine engel olmak için tibial baseplate uzatma stemi ve femoral komponent stemi dışındaki tüm stemler yakalıklıdır. Tibial baseplate uzatma stemi ve femoral komponent stemi zaten tamamen kemik içinde gömülü olduğundan yakalığa gerek bulunmamaktadır.

Stemlerin, anatomik eğimli ve düz versiyonları bulunmaktadır. Femoral stemlerin 12-22 mm arası çaplarda ve 120$150-200 \mathrm{~mm}$ uzunluklarda, tibial stemlerin ise $11-20 \mathrm{~mm}$ arası çaplarda ve $120 \mathrm{~mm}$ uzunlukta seçenekleri vardır.

Tüm Penta-MUTS stem, gövde ve uzatma parçaları, Penta-MUTS'a özgü bir rotasyon - ayar mekanizmasıyla birleştirilebilmektedir. Modüller arasındaki bağlantı, $6^{\circ}$ 'lik aralarla rotasyonun ayarlanabildiği, press-fit konik 
kilitlenen ve aksiyel bir transfiksasyon vidası ile nihai olarak sabitlenen 3'lü bağlantı kombinasyonu ile sağlanmaktadır. Transfiksasyon vidası, modüller arasında ayrışma riskini ortadan kaldırmaktadır. Rotasyon ayar sistemi, rotasyonun kolaylıkla ve hassas şekilde ayarlanabilmesine olanak sağlar, bağlantı noktasında rotasyonel stabiliteye katkıda bulunur. Konik bağlantı, modüler arasında bağlantı noktasında bükülme kuvvetlerine karşı direnç oluşturur. Uzatma parçaları, 1 'er santimetrelik artışarla implant boyunun ayarlanmasına izin vermektedir.

Sistemde, ultra yüksek molekül ağırlıklı polietilenden (UHMWPE) üretilen insertler (tibial insert, bumper insert) kullanılmaktadır. UHMWPE, ASTM F 648 ve ISO 5834$1 / 2$ standartlarina uymaktadir. UHMWPE, standart polietilene göre daha yüksek aşınma direnci ortaya koyar.

Diz eklem menteşesi, tibial rotasyon parçasının üzerine geçirilen ve femoral gövde veya femoral komponenti hiperekstansiyonda bloke ederek ekstansiyonu sonlandiran bumper insert bulunması ile karakterizedir. Bumper insert, standart $\left(0^{\circ}\right)$ ve $5^{\circ}$ hiperekstansiyon seçeneklerine sahiptir. Hiperekstansiyonlu insert, geniş adale rezeksiyonları nedeniyle ekstansör mekanizmanın zayıfladığı durumlarda dizin kilitlenebilmesini sağlamaktadır.

Distal femur gövde parçası, anatomik (sağ ve sol) yapıda olup $5^{\circ}$ valgus açısına sahiptir. Proksimal tibia rezeksiyon protezinin femoral komponent kesileri, kondillerdeki kemik stoğu azami oranda korunacak ve femoral komponent kondillere gömülecek şekilde tasarlanmıştır. Bu şekilde hem komponentin stabilitesi artmakta hem de ileride gerekebilecek revizyon ve kurtarma girişimleri için daha fazla kemik stoğu korunmaktadır. Distal femoral komponent ve tibial baseplate parçalarının boyut seçenekleri mevcuttur.

Proksimal femur gövde parçasının şaft-boyun açısı $135^{\circ}$ 'dir. Proksimal femur ve distal femur gövdeleri özel bir şaft ile birleştirilerek total femur rekonstrüksiyonu sağlanabilmektedir.

Proksimal humerus gövde parçasının şaft-boyun açısı $135^{\circ}$ 'dir. Proksimal ve distal humerus gövde parçaları ile uzatmaları kendi içinde uyumludur ve total humerus rekonstrüksiyonu sağlanabilmektedir. Dirsek ekleminin rekonstrüksiyonu için ulnar bir komponent bulunmaktadır ve dirsek eklemi humeroulnar fikse menteşe şeklinde çalışmaktadır. Humeral stemlerin boyи 90 mm'dir.

Proksimal femur, proksimal humerus ve proksimal tibia gövde parçalarında, yumuşak doku bağlantılarının yapılabilmesi için dikiş delikleri bulunur."

\section{İstemler ${ }^{[8]}$}

"1. Buluş, omuz, kalça, diz ve dirsek eklemleri ile bu eklemlere komşu humerus, femur ve tibia kemiklerinde başta tümör rezeksiyonu olmak üzere, revizyon artroplastisi, çok parçalı kırıklar, çoklu bağ yaralanması ve deformite gibi nedenlere bağlı olarak ortaya çıkan tamir edilemeyecek kemik ve eklem kayıpları ile kronik eklem instabilitelerinde rekonstrüksiyonu sağlayabilecek bir modüler megaprotez sistemini içermektedir.

2. İstem 1'e göre sistemin parçalarının uzun kemiklerin (humerus, femur, tibia) medüller kanalına tespit edilmesini sağlayan stem (protez sapı), beşgen (pentagonal) kesitli olması ve uç kısma doğru konik şekilde daralması ile karakterizedir (Şekil 3 ve 4).

3. İstem 2'de bahsedilen stemin bağlantı noktası ile stemin gövdesi arasında, stemin kemiğin medüller kanalına gömülmesine engel olacak bir yakalık bulunması ve bu yakalığın medüller kanala bakan alt tarafinda stem gövdesiyle oval eğimli bir geçiş sağlayan yüzeyler bulunması ile karakterizedir (Şekil 4).

4. İstem 2'de bahsedilen stem, anatomik eğimli ve düz versiyonları bulunacak, femurda 12-22 mm arası çaplarda ve 120-150-200 mm uzunluklarda, tibiada 11-20 $\mathrm{mm}$ arası çaplarda ve $120 \mathrm{~mm}$ uzunlukta seçenekleri, humerusta ise $90 \mathrm{~mm}$ boyunda olacak şekilde tasarlanmıştır. Stemler, titanyumdan üretilmiş olmaları, çimentosuz uygulama için hidroksiapatit (HA) kaplı, çimentolu uygulama için ise kaba kumlamalı yüzeye haiz olmaları ile karakterizedir (Şekil 4). Femoral komponent stemi ve tibial baseplate uzatma steminde istisnai olarak yakalık bulunmayacaktır.

5. İstem 1'e göre sistemin diz eklemini rekonstrükte eden parçaları, fizyolojik diz hareketini taklit edecek şekilde 16 derece iç ve dış rotasyona izin veren kontrollü rotasyonel menteşe yapısıyla karakterizedir (Şekil 5).

6. Istem 4'te bahsedilen rotasyonel menteşe, tibial rotasyon parçasının alt yüzeyindeki iki adet rotasyon sınırlayıcı çıkıntının (23.1), tibial insert üzerindeki kanallar (26.1) içerisinde hareket etmesiyle karakterizedir. Konkav yapıdaki tibial insert üst yüzeyi (26.3), uç noktalarda rotasyon hareketini yavaşlatarak durduracak şekilde tibial rotasyon parçasının konveks alt yüzeyi (23.3) ile eşleşmektedir (Şekil 5).

7. İstem 4'te bahsedilen rotasyonel menteşe, tibial rotasyon parçasının üzerine geçirilen ve femoral gövde veya femoral komponenti hiperekstansiyonda bloke ederek ekstansiyonu sonlandiran bumper insert bulunması ile karakterizedir. Bumper insert, standart $\left(0^{\circ}\right)$ ve $5^{\circ} \mathrm{hi}$ perekstansiyon seçeneklerine sahiptir (Şekil 6).

8. İstem 1'e göre sistemin tüm stem, gövde ve uzatma parçaları arasındaki bağlantı mekanizması, 6 derecelik aralarla rotasyonun ayarlanabildiği, press-fit konik kilitlenen ve aksiyel bir transfiksasyon vidası ile nihai olarak sabitlenen 3'lü bir kombinasyon ile karakterizedir (Şekil 7). Uzatma parçaları, 1'er santimetrelik artışlarla 
implant boyunun ayarlanmasına izin vermektedir. Ayrıca sistemin tüm stem, gövde ve uzatma parçaları Ti6Al-4V alaşımdan, yalnızca proksimal tibia rezeksiyon protezinin femoral komponenti CoCrMo malzemeden üretilecek şekilde tasarlanmıştır.

9. İstem 1'e göre sistemin distal femur gövdesi $5^{\circ}$ valgus, proksimal femur ve proksimal humerus gövdeleri ise $135^{\circ}$ şaft-boyun açısı ile karakterizedir. Proksimal tibia rezeksiyon protezinin femoral komponent kesileri, kondillerdeki kemik stoğu azami oranda korunacak ve femoral komponent kondillere gömülecek şekilde tasarlanmıştır.”

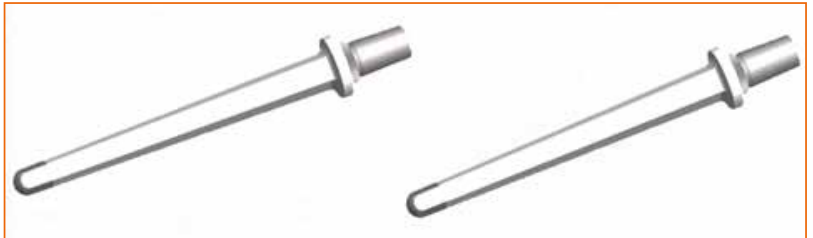

Şekil 3. Beşgen (pentagonal) kesitli stemlere ait çizimler görülmekte.

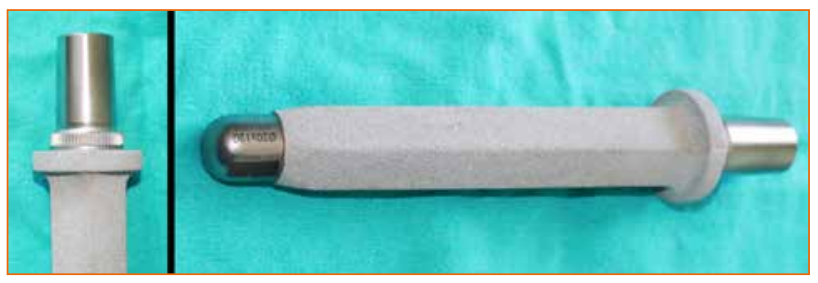

Şekil 4. Üretimi gerçekleştirilmiş bir protez sapında yakalık, yakalığın üstündeki dişli ve konik bağlantı, yakalığın altındaki eğimli yüzey ve hidroksiapatit (HA) kaplamaya ait detaylar görülmekte.

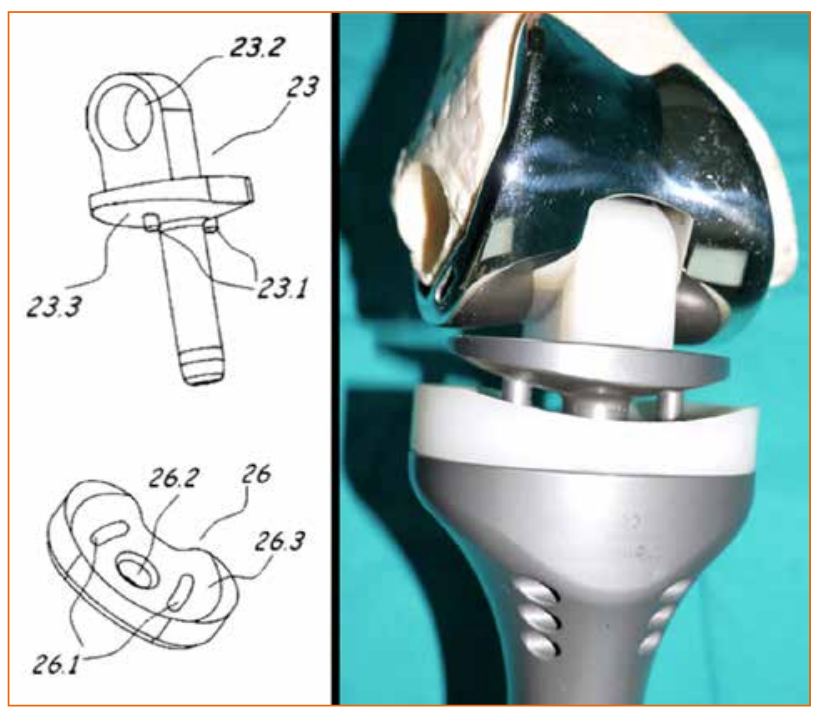

Şekil 5. Solda tibial rotasyon parçası (23) ve tibial insert (26) çizimleri görülmekte. Sağda ise üretimi gerçekleştirilmiş komponentlerin proksimal tibia defektli iskelet modeli üzerine uygulanmasıyla rotasyonel menteşenin oluşturulduğu görülmekte.

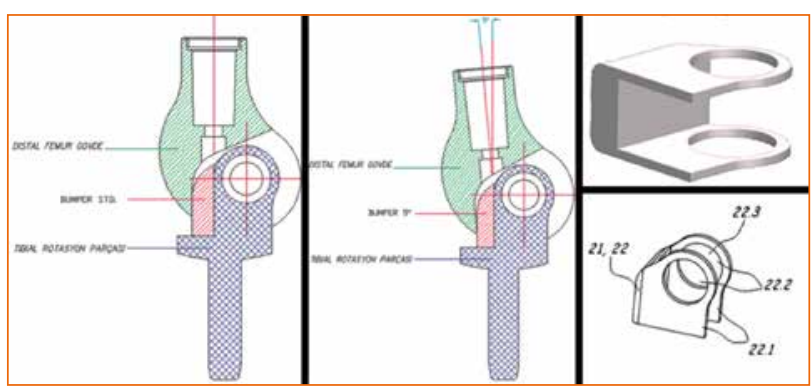

Şekil 6. UHMW-PE'den üretilmiş olan bumper insert, tibial rotasyon parçasının anterior kısmında bir tampon vazifesi görerek distal femur gövdesini veya distal femur komponentini tam ekstansiyonda veya $5^{\circ}$ hiperekstansiyonda kısıtlayacak şekilde tasarlanmıştır.

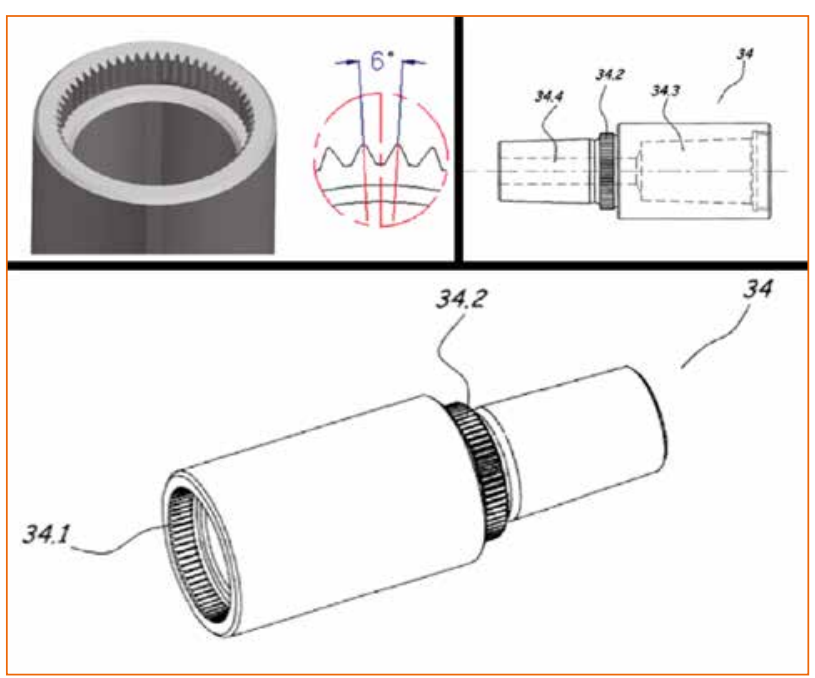

Şekil 7. Çizimlerde, megaprotez sistemine ait bir uzatma parçası görülmekte. Uzatma parçasının bir ucu dişi, bir ucu erkek yapıda olup her iki ucu da $6^{\circ}$ lik aralarla rotasyonun ayarlanabildiği, press-fit konik kilitlenen yapıya sahiptir. Ayrıca uzatma parçasının içindeki kanaldan geçirilen aksiyel transfiksasyon vidası ile nihai kilitleme yapılabilmektedir.

\section{YAZARIN KONUYLA ILGILI ÇALIŞMALARI}

1. Özger H, Baş A, Alpan B, Eralp L. Penta Modüler Uzuv Tamir Sistemi (PentaMUTS): Yeni bir tümör protezi ve erken dönem sonuçlar. 5. Ortopedi Buluşması, Antalya, 21-25 Nisan, 2010.

2. Özger $\mathrm{H}$. The Evolution of Modular Tumor Prosthesis Reconstruction: Modes of Failure and Sophisticated Solutions According to Design and Technique. Congreso SLATME (Sociedad Latino Americana de Tumores Musculoesqueléticos), Peru, Şili, 15 Eylül 2015.

3. Özger H, Alpan B, Aycan OE, Valiyev N. The Survival and Functional Outcomes ofPENTA-MUTSTumor Endoprosthesis around the Knee: Times Change and Prosthesis with Time. ISOLS (International Society of Limb Salvage) Conference, Kanazawa, Japonya, 10-12 Mayıs, 2017.

4. Alpan B, Aycan OE, Valiyev N, Özger H. Hepsi Gerçekten Metallozis Mi? Diz Çevresi Tümör Protezi Revizyonlarında Metallozis Gelişen Hastalarda Sinoviya Benzeri Arayüz Membranının (SLIM) Histopatolojik Değerlendirilmesi. 28. Ulusal Türk Ortopedi ve Travmatoloji Kongresi, Antalya, 30 Ekim - 4 Kasım 2018. 


\section{KAYNAKLAR}

1. Ozger $\mathrm{H}$, Eralp L, Atalar AC, Toker B, Ayan I, Kebudi $R$, Bağbek $S$, Başaran $M$, Ağaoğlu $F$, Dizdar $Y$, Bilgiç $B$. Survival analysis and the effects of prognostic factors in patients treated for osteosarcoma. Acta Orthop Traumatol Turc 2007;41:211-9. http://aott.org.tr/files/journals/1/ articles/2802/public/2802-3535-1-PB.pdf

2. Ruggieri P, Bosco G, Pala E, Errani C, Mercuri M. Local recurrence, survival and function after total femur resection and megaprosthetic reconstruction for bone sarcomas. Clin Orthop Relat Res 2010;468:2860-6. Crossref

3. Pala E, Trovarelli G, Calabrò T, Angelini A, Abati CN, Ruggieri P. Survival of modern knee tumor megaprostheses: failures, functional results, and a comparative statistical analysis. Clin Orthop Relat Res 2015;473:891-9. Crossref

4. Ahlmann ER, Menendez LR, Kermani C, Gotha H. Survivorship and clinical outcome of modular endoprosthetic reconstruction for neoplastic disease of the lower limb. J Bone Joint Surg Br 2006;88-B:790-5. Crossref
5. Gosheger G, Gebert C, Ahrens H, Streitbuerger A, Winkelmann W, Hardes J. Endoprosthetic reconstruction in 250 patients with sarcoma. Clin Orthop Relat Res 2006;450:164-71. Crossref

6. Zeegen EN, Aponte-Tinao LA, Hornicek FJ, Gebhardt MC, Mankin HJ. Survivorship analysis of 141 modular metallic endoprostheses at early followup. Clin Orthop Relat Res 2004;420:239-50. Crossref

7. Toker B. Diz Çevresinde Uygulanan Rotasyonlu Rotasyonsuz Tümör Protezlerinin Klinik Sonuçlarının Yürüme Analizi Katkısıyla Karşılaştırılması. İstanbul: İstanbul Üniversitesi, İstanbul Tıp Fakültesi, Tıpta Uzmanlık Tezi, 2009. http://nek. istanbul.edu.tr:4444/ekos/TEZ/45912.pdf

8. Protez Sisteminde Yenilik. T. C. Türk Patent Enstitüsü. Faydalı Model Belgesi. No: TR 2010 06456. https://portal. turkpatent.gov.tr/anonim/arastirma/patent/detayli 